\title{
Análise das condičões de vida de famílias beneficiárias de programas de transfêrencia de renda no Brasil: 2008-2009
}

Ana Maria Segall Corrêa ${ }^{1}$

Daniela Gonçalves Lenci²

1 Professora Livre Docente, colaboradora do curso de pós-graduação em Saúde Coletiva da Universidade Estadual de Campinas (UNICAMP) e consultora da Secretaria de Avaliação e Gestão da Informação do Ministério do Desenvolvimento Social e Combate à Fome (SAGI-MDS). Contato: amsegall@uol.com.br. 


\section{Resumo}

ESTE TRABALHO REFERE-SE À ANÁlISE SECUNDÁRIA DE DADOS DA PESOQUISA DE ORÇAMENTOS FAMILIARES DO IBGE, REALIZADA NOS ANOS DE 2008/2009 E PUBLICADA EM 2010. BUSCOU-SE NESTAS ANÁLISES CLAREAR AS CONDIÇÕES DE VULNERABILIDADE SOCIAL, DEMOGRÁFICA E ECONÔMICA, PRESENTES EM GRANDE PARTE DOS DOMICÍLIOS ONDE RESIDEM PESSOAS VINCUAbstract LADAS AOS PROGRAMAS FEDERAIS Bolsa Família (PBF) e Benefício de Prestação Continuada (BPC). AS INFORMAÇÕES SOCIAIS, DEMOGRÁFICAS, DE DESPESA, CONSUMO E OUALIDADE DE VIDA PERCEBIDA, RELATIVAS AOS DOMICÍLIOS DESTES DOIS GRUPOS FORAM COMPARADAS ENTRE SI E ENTRE OS DEMAIS DOMICÍLIOS DA AMOSTRA. OS RESULTADOS MOSTRARAM, EM TODAS AS REGIÕES DO PAÍS, CONDIÇÕES MAIS DESFAVORÁVEIS, PORTANTO, MAIOR VULNERABILIDADE, ENTRE AS FAMÍLIAS TITULARES DE TRANSFERÊNCIA DE RENDA DO PBF. RESTRIÇÕES AMOSTRAIS DIFICULTARAM ALGUMAS ANÁLISES RELATIVAS AOS TITULARES DO BPC; MESMO ASSIM E, SEMELHANTEMENTE AOS OQUE ESTÃO LIGADOS AO PBF, AS INFORMAÇÕES GERADAS PELAS ANÁLISES AOQUI RELATADAS SÃO RELEVANTES PARA A ORIENTAÇÃO DAS POLÍTICAS PÚBLICAS.

ANALYSIS OF EXPENDITURE OF LOW INCOME FAMILIES ELIGIBLE FOR SOCIAL CASH TRANSFER PROGRAMS: BRAZIL-POF 2008-2009

THIS PAPER REPORTS A SECONDARY DATA ANALYSIS OF THE National Survey on Family EXPENDItURE (POF) CARRIED OUT BY IBGE IN THE YEARS 2008/2009 AND PUBLISHED IN 2010. FAMILY DWELLINGS WERE ASSOCIATED WITH DEMOGRAPHIC, ECONOMIC AND SOCIAL VULNERABILITY CONDITIONS THAT WERE FOUND AMONG THOSE DEPENDING ON FEDERAL CASH TRANSFER PROGRAMS TARGETING POOR FAMILIES (PBF) AND PEOPLE WITH PERMANENT SOCIAL RESTRAINS, DEPRIVING, IMPAIRMENT AND DISABILITY (BPC). A COMPARISON WAS MADE BETWEEN PEOPLE FROM FAMILY DWELLINGS IN AND OUT OF PBF/BPC WITH REGARDS TO SOCIAL INFORMATION, DEMOGRAPHY, EXPENDITURES, GOODS CONSUMPTION AND PERCEIVED QUALITY OF LIFE. RESULTS HAVE SHOWN THAT IN EVERY REGION IN THE COUNTRY, THE FAMILIES UNDER THE PBF WERE MORE VULNERABLE AND EXPERIENCED UNFAVORABLE CONDITIONS. SAMPLING RESTRICTIONS PREVENTED ANALYTICAL INFERENCE ON THOSE UNDER BPC, BUT EVEN THEN THEY BEHAVE SIMILAR TO THOSE USING PBF AND THESE ANALYSES ARE RELEVANT INFORMATION TO DIRECT PUBLIC POLICIES.

\section{PALAVRAS-CHAVE:}

Bolsa Família; Benefício de Prestação Continuada; Despesa Familiar; Condição de vida; Transferência de Renda

Revista Brasileira de Monitoramento e Avaliação | Número 4 | Julho-Dezembro de 2012

Análise do consumo de famílias de baixa renda elegiveis aos programas sociais de transferência de renda: Brasil-POF 2008-2009 


\section{Introdução}

A realização da Pesquisa de Orçamentos Familiares (POF) pelo Instituto Brasileiro de Geografia e Estatística (IBGE) traz valiosas informações sobre as condições de vida da população brasileira. Essas informações são baseadas na estrutura do consumo das famílias, nos seus gastos e orçamentos domésticos, nas variações patrimoniais e, ainda, nas condições de nutrição ${ }^{3}$. A periodicidade da POF tem permitido, além do diagnóstico de situação, o acompanhamento das variações nos indicadores de qualidade de vida da população brasileira e suas desigualdades territoriais, de gênero, raça/cor, entre outras.

A primeira POF foi realizada em 1974-1975 e com as quatro subsequentes foi possível observar a evolução dos indicadores de condições de moradia, saneamento, saúde e nutrição, mesmo considerando diferenças de abrangência e objetivos específicos de algumas dessas pesquisas ${ }^{4}$. Seus resultados possibilitaram, ainda, analisar a composição dos gastos familiares por região geográfica, situação rural ou urbana do domicílio, perfil de rendimentos e características demográficas, o que enseja detalhar as iniquidades sociais tão conhecidas no Brasil. A última POF realizada em 2008-2009 agregou indicadores que, juntamente com os tradicionais existentes, fortaleceram o uso dessas informações para a formulação de políticas públicas novas e o monitoramento do impacto das existentes. É neste contexto que estão disponíveis nesta pesquisa de orçamento familiar informações sobre o consumo efetivo de alimentos e não apenas estimativas de consumo por meio dos gastos com alimentos; sobre participação dos grupos populacionais nas políticas públicas e programas sociais do País, como no Programa Bolsa Família (PBF), no Benefício de Prestação Continuada (BPC) e no Programa Nacional de Alimentação Escolar (PNAE), além de informações sobre a percepção de aspectos ligados à qualidade de vida.

Seus resultados mostraram que a despesa média das famílias brasileiras estava em torno de 2,6 mil reais, com desigualdades regionais importantes e já conhecidas, como mostra a redução dos gastos para 1,7 mil reais entre as famílias residentes no Nordeste e elevação para mais de três mil reais naqueles que moram no Sul e Sudeste. As desigualdades nas possibilidades de consumo das famílias brasileiras estimadas a partir de suas despesas são muito evidentes quando analisados os rendimentos médios mensais. Famílias com rendimento mensal total superior a 10 mil reais possuem despesa total média de $14 \mathrm{mil}$ reais e aquelas cujos rendimentos são de até 830 reais têm despesas mensais de apenas 144 reais, portanto, com possibilidades muito reduzidas de consumo de bens e serviços, mesmo os mais essenciais.

Também as despesas dos domicílios urbanos superam o dobro do observado naqueles situados em áreas rurais. Estas disparidades ficam mais evidentes e graves quando é analisado o perfil de despesas de consumo. Nos domicílios brasileiros, a média de gastos com o consumo é de 2,1 mil reais, já na área rural é quase a metade (1,2 mil reais). Isto corresponde a $57 \%$ das despesas médias de consumo nacional e a $53 \%$ da despesa verifica- 
da em área urbana. A desigualdade atinge, consequentemente, as despesas de consumo com a alimentação. No Brasil, essas despesas representam em termos médios 19,8\% das despesas totais. Na área rural, a despesa com alimentação compromete $27,6 \%$ dos rendimentos familiares, no Nordeste $26 \%$. Entre as famílias com rendimentos de até 830 reais, esse comprometimento do rendimento com alimentação é de $27,8 \%$.

Algumas características sociais e demográficas da população reforçam a compreensão da desigualdade apontada. Quando a mulher é a pessoa de referência da família, a média das despesas familiares é de 2,2 mil reais, passando a 2,8 mil nos demais domicílios. Se a pessoa de referência é de cor autodeclarada preta ou parda, este valor cai pra 1,7 mil reais. Ter possibilidade de chegar ao fim do mês com os recursos necessários para a alimentação também reflete essas disparidades. Em geral, 17,9\% das famílias referiram muita dificuldade e na área rural o percentual sobe para $22,1 \%$. Insuficiência de quantidade de alimentos consumidos ocorreu em 51,5\% e $49,8 \%$ das famílias do Norte e Nordeste, respetivamente. No Sul, essa insuficiência na quantidade de alimentos baixa para 22,9\%.
Pesquisadores têm analisado também o perfil de consumo efetivo de alimentos a partir de análise secundária dos dados da POF, sobretudo de 2002-2003 e de 2008-2009. Os resultados desta última POF mostram consumo suficiente de proteínas, porém excesso de consumo de açúcares, refrigerantes e gorduras saturadas, ao lado de baixo consumo de frutas e verduras 5 e desigualdades de consumo tomando como referência as regiões brasileiras e o perfil sociodemográfico da população. Estudos que analisam a evolução do padrão dietético da população usando os dados das POFs enfatizam a mudança no padrão de consumo alimentar no País e os riscos para a saúde e bem-estar que isto acarreta ${ }^{6}$.

Outras informações importantes para as políticas públicas brasileiras poderão ainda ser geradas a partir dos bancos de dados da POF. Destacamos aqui a necessidade de análise mais aprofundada do perfil de consumo das famílias brasileiras, sobretudo dos grupos mais vulneráveis, entre eles os sujeitos de ações dos programas sociais de enfrentamento da pobreza absoluta e da insegurança alimentar.

Buscando atender a essa necessidade, o estudo aqui relatado disponibiliza as caracterís-

3 (IBGE, 2010.)

4 (IBGE, 2004; IBGE, 2010.)

5 LEVY B. et al, 2011.)

6 (COELHO AB et al, 2009; LEVY-COSTA RB et al, 2005.)

Revista Brasileira de Monitoramento e Avaliação | Número 4 | Julho-Dezembro de 2012 
ticas sociais e demográficas ligadas especialmente às condições de moradia, rendimentos médios, classificação econômica e perfil de despesas das famílias beneficiárias de transferência de renda do PBF e do BPC. Além disso, apresenta a percepção dos entrevistados sobre itens ligados à sua condição de vida, como rendimentos em condição de atender às necessidades de consumo mensal das famílias, grau de suficiência de alimentos disponíveis no domicílio para consumo familiar e satisfação com o tipo de alimentos consumidos.

\section{Métodos}

O estudo foi realizado a partir de análise secundária de dados da POF 2008-20097. Segundo publicação do IBGE', adotou-se para essa POF um plano amostral de conglomerados em dois estágios, com estratificação geográfica e estatística das unidades primárias de amostragem que correspondem aos setores da base geográfica do Censo Demográfico de 2000, a partir da estrutura já planejada para o Sistema Integrado de Pesquisas Domiciliares. Os setores amostrados foram selecionados com probabilidade proporcional ao número de domicílios existentes no setor. Os domicílios em cada setor (unidade da amostra) foram selecionados em processo aleatório simples. Foram utilizados pesos para ajustes amostrais relativos a não respostas e para expansão da amostra para o total da população estimada para janeiro de 2009.

Para as análises apresentadas neste relatório foram inicialmente incluídos 13.569 domicí- lios. Destes foram excluídos 748 por terem mais de uma família moradora, bem como outros 43 por receberem simultaneamente transferências de renda do BPC e PBF. Os restantes 12.778 foram divididos em 2.076 domicílios com PBF e 209 com BPC, os outros 10.493 sem qualquer dos dois benefícios. A exclusão dos primeiros 748 deveu-se ao fato de que a opção foi por tomar o domicílio como unidade de análise. A existência de mais de uma família poderia incluir viés nos resultados relativos ao compartilhamento total ou em parte dos recursos advindos das transferências de renda.

Nesta etapa do trabalho, foram usados exclusivamente procedimentos de análise descritiva, com resultados representativos para a amostra (resultados não expandidos), explorando os seguintes indicadores:

1. Características da unidade domiciliar dos titulares do PBF e BPC e de não titulares do mesmo estrato social.

2. Características sociais e demográficas dos moradores - titulares do PBF e BPC e de não titulares do mesmo estrato social.

3. Aquisição coletiva - relativas aos titulares do PBF e BPC e não titulares do mesmo estrato social (POF 2 - Item 14 - Inventário de bens duráveis do domicílio principal).

4. Trabalho e rendimento familiar - dos titulares do PBF e BPC e de não titulares do mesmo estrato social (POF 5 - Item 53 e 54). 
5. Despesas correntes, monetárias e não monetárias, suas médias mensais, despesas com alimentação, habitação, transporte e outras (além de gastos médios com itens alimentares).

6. Avaliação da qualidade de vida dos titulares do PBF e BPC e de não titulares do mesmo estrato social (POF 6).

O artigo apresenta as tabulações básicas com cruzamento das variáveis de interesse sempre agrupadas por condição de participação em cada um dos programas sociais, objeto dessa análise. As variáveis dicotômicas relativas ao PBF e ao BPC usadas nos cruzamentos com outras de interesse foram elaboradas a partir das variáveis de valores contínuos, incluindo como resposta positiva qualquer valor referido pelo entrevistado. Foram necessários outros procedimentos de programação para a reestruturação de algumas variáveis contínuas em categóricas e de redefinição dos estratos das variáveis categóricas.

Para integrar os diversos bancos de dados da POF, foram necessários procedimentos com definição de métodos para seleção das variáveis relativas a "domicílios e pessoas" (POF1), conteúdos de módulos "aquisição coletiva" (POF2), "despesas e inventário de bens durá- veis" (POF2), "rendimentos" (POF5) e "qualidade de vida" (POF 6), em um processo sequencial de acordo com o critério de inclusão para as análises propostas.

\section{Resultados e discussão}

A análise das informações sociais e demográficas, de despesas totais e de consumo, inclusive alimentares, de titulares do PBF e BPC contidas na POF 2008/2009 foi feita com um total de 12.778 domicílios, dos quais 2.076 tinham moradores que recebiam apenas recursos do PBF e 209 apenas do BPC, restando 10.493 domicílios onde não estava presente qualquer destes dois benefícios.

A descrição das condições sociais observadas nos domicílios com pessoas que recebem transferência de renda (TR) do PBF e BPC aponta maiores vulnerabilidades, sobretudo para o primeiro grupo. As condições de moradia são mais precárias, tanto pelas características construtivas das habitações, que têm percentual menor de paredes de alvenaria e maior de piso inadequado, quanto pelas características dos serviços de saneamento. A disponibilidade de água por rede de distribuição está presente em $76 \%$ dos domicílios que não recebem TR do PBF, diminuindo para $66 \%$ entre

$7 \quad$ (IBGE, 2010.)

$8 \quad$ (IBGE, 2010.)

Revista Brasileira de Monitoramento e Avaliação | Número 4 | Julho-Dezembro de 2012 
os que recebem. Ausência de banheiros tem, também, percentual maior entre estes últimos. É baixa para toda a população a disponibilidade de esgotamento sanitário por meio de rede coletora, mas o percentual cai pela metade em domicílios onde há titulares do PBF.

A transferência de renda do PBF, como esperado, é mais frequente para os domicílios das classes econômicas mais baixas ${ }^{9}$. Nesses domicílios, 76\% são classificados nos estratos $D$ e E, enquanto nos domicílios onde não há titulares desta transferência este percentual é de 41\%. Distribuição percentual alta nessas classes econômicas também é observada nos domicílios cujos moradores recebem TR do BPC (70\%).

Resultados semelhantes já haviam sido observados na Pesquisa Nacional por Amostra de Domicílios (PNAD) de 2004 e de 2008/200910 e na Pesquisa Nacional de Demografia e da Saúde da Mulher e Criança (PNDS) de $2006^{11}$. São resultados que confirmam relatos que a distribuição dos recursos oriundos dos programas sociais do governo federal está, de fato, dirigida à população em condições de maior vulnerabilidade social e econômica.
A pior condição social e econômica dos domicílios onde estão presentes titulares do programa de TR do PBF é confirmada na análise de distribuição de rendimentos. Em todas as regiões do Brasil, o rendimento familiar mensal per capita (RFMPC) de 50\% dos domicílios (mediana) onde residem titulares do PBF é sistematicamente menor, comparativamente aos demais domicílios (gráfico 1). A diferença no percentual de renda entre os grupos de titulares chega a ser de $64 \%$ nas regiões Sul e Sudeste, de $62,5 \%$ na região Nordeste e de $57 \%$ nas regiões Norte e Centro-Oeste. Também são estatisticamente significativas as diferenças quando é comparado o RFMPC auferido nas áreas urbanas e rurais de cada uma das macrorregiões. As medianas de renda familiar per capita são maiores nas áreas urbanas comparativamente às rurais, sendo as diferenças da ordem de $32,5 \%$ na região Sul, na região Norte de $23,1 \%$, na região Nordeste de $20,2 \%$, de $14,4 \%$ e $11,1 \%$ nas regiões Centro-Oeste e Sudeste, respectivamente. Pode-se afirmar que todas essas diferenças, tanto entre regiões como entre áreas urbanas e rurais de cada região, seriam maiores se no rendimento familiar dos titulares não estivessem incluídos os valores das transferências de renda. 


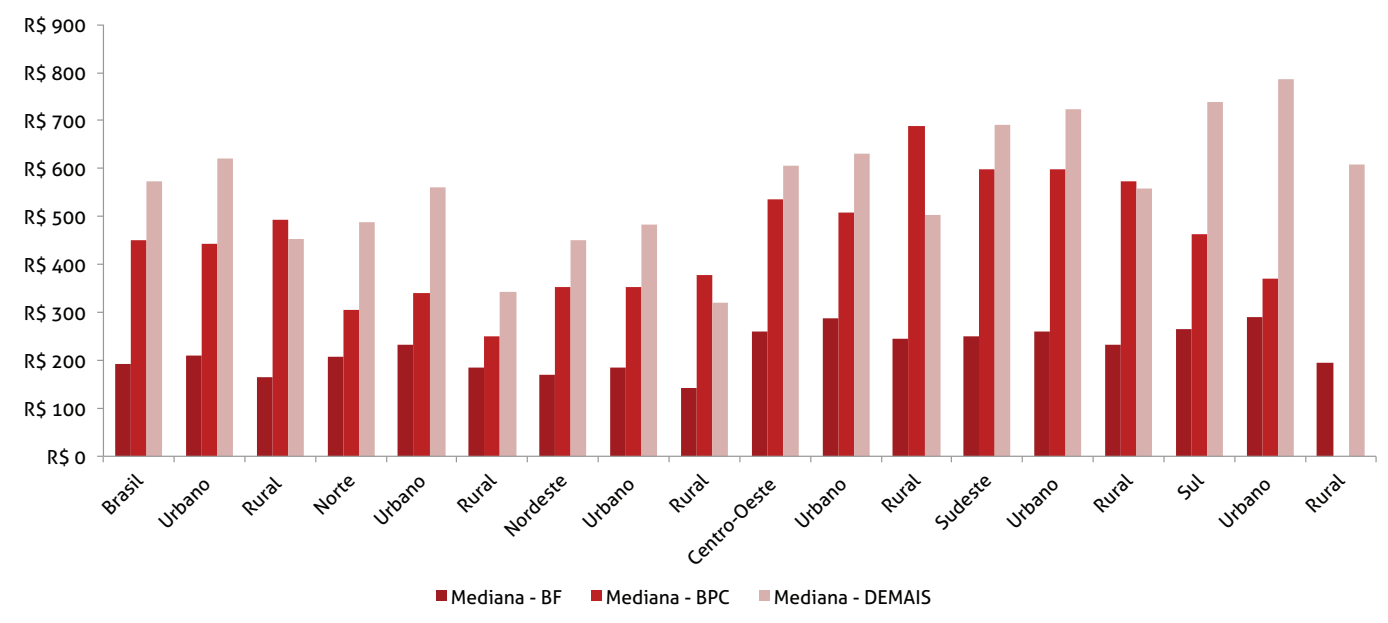

Fonte IBGE POF2008-2009

Gráfico produzido pelas autoras

Considerando os valores para o País, os rendimentos familiares per capita no primeiro quartil de renda (os 25\% mais pobres) são 2,8 vezes menores nos domicílios que recebem PBF, comparativamente aos que não recebem. Essa razão permanece próxima deste patamar em todas as regiões e em áreas rurais e urbanas. São valores de rendimento familiares que não garantem, neste grupo, o atendimento às necessidades básicas de consumo, inclusive de alimentação (dados não mostrados no gráfico). Ao analisar as mesmas condições nos grupos que recebem e não recebem TR do $B P C$, os resultados não espelham o mesmo padrão do PBF. Observa-se que as diferenças, comparando as medianas dos rendimentos mensais per capita em área rural e urbana, são menos discrepantes que nos domicílios do PBF (gráfico 2). Na região Norte, a diferença percentual entre rural e urbano é de $26,1 \%$ e de apenas 4,6\% no Sudeste, ambos percentuais favorecendo os domicílios de área urbana. Já os percentuais de diferença nos rendimentos medianos favorecendo as áreas rurais são de $26,3 \%$ e 6,8\% no Centro-Oeste e Nordeste, respectivamente. Por outro lado, as comparações entre domicílios que recebem e aqueles que não recebem TR do BPC, em cada uma das

\section{9 (ABEP, 2008.)}

10 (IBGE, 2006; IBGE, 2010.)

11 (SEGALL-CORREA et al, 2008.)

Revista Brasileira de Monitoramento e Avaliação | Número 4 | Julho-Dezembro de 2012 
regiões, mostram que esta transferência de renda pode ter impactado positivamente o rendimento na área rural. Com exceção da região Norte, os rendimentos familiares per capita medianos são mais elevados nas áreas rurais das regiões Nordeste, Centro- Oeste e Sudeste. Não há registro de BPC na área rural da região Sul.

Uma observação importante derivada destes resultados é sobre a diferença de rendimentos dos domicílios com PBF e aqueles com BPC. A mediana de rendimentos familiares mensais per capita nos domicílios onde está presente o PBF é 57\% menor que o valor mediano dos domicílios com BPC. O rendimento do primeiro quartil ( $25 \%$ da população mais pobre) é de apenas $R \$ 118,00$, elevando para R\$ 278,00 nos domicílios onde ocorre o BPC e para R\$329 nos domicílios sem estas transferências (dados não mostrados gráfico). A veri- ficação das condições de vulnerabilidades dos grupos populacionais incluídos no PBF e no BPC requer, entretanto, estabelecer condições de comparabilidade com os grupos não incluídos, definidas aqui por limite nos rendimentos familiares per capita mensais de dois salários mínimos $^{12}$ (SM). Os resultados mostram que mesmo neste limite de rendimentos os indicadores sociais, econômicos e de ambiente domiciliar apontam maior vulnerabilidade nos domicílios onde seus moradores recebem PBF, exceto para o tipo e cobertura adequada da moradia, comparativamente aos demais. Os domicílios onde existe recebimento de TR oriundo do BPC têm condições sociais mais favoráveis e pouco se diferenciam daqueles domicílios que, por razões de elegibilidade, os benefícios do BPC e do PBF não estão presentes. Algumas dessas condições de vulnerabilidade estão colocadas no gráfico 2.

- GRÁFICO 2: CONDIÇÕES SOCIAIS E DE MORADIA DE BENEFICIÁRIOS DO PBF, BPC E NÃO BENEFICIÁRIOS NO ESTRATO DE RENDA ABAIXO DE DOIS SALÁRIOS MÍNIMOS MENSAIS PER CAPITA (VALOR DO SM RS 415,00) - BRASIL

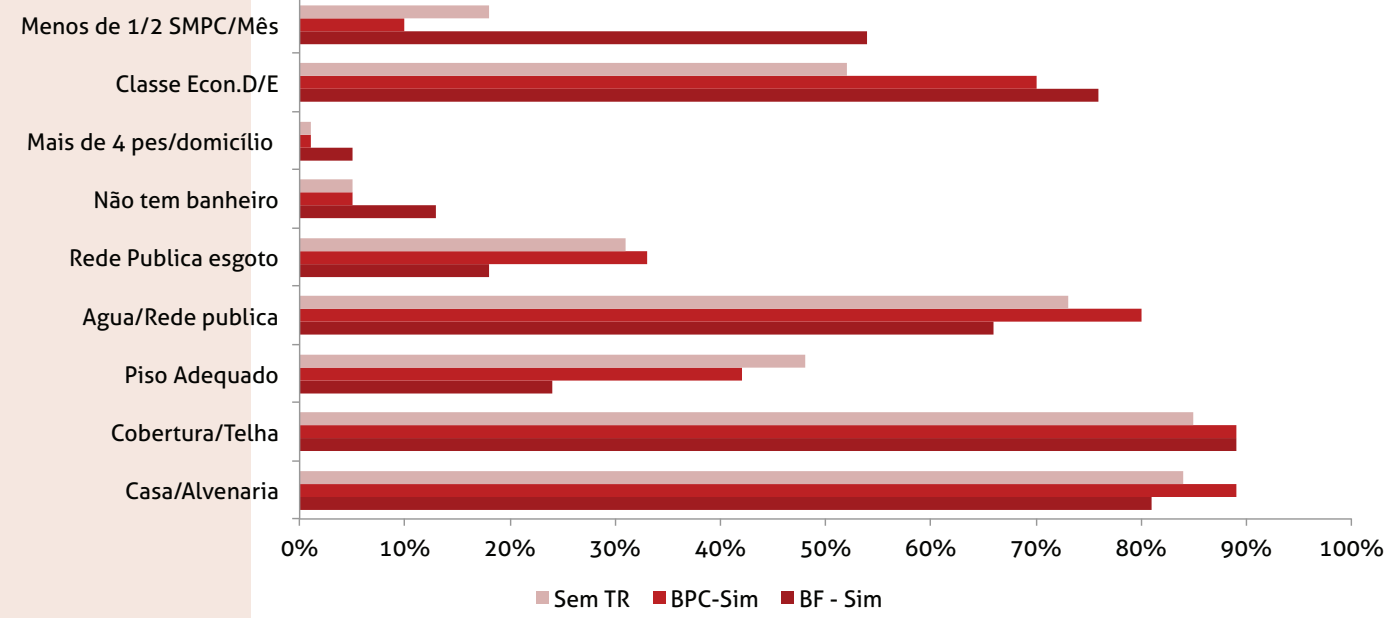

Fonte IBGE POF2008-2009

Gráfico produzido pelas autoras 
Proporção maior desta população vive em habitações com maior disponibilidade de serviços públicos de fornecimento de água e de esgotamento sanitário. Também é maior a proporção de famílias pequenas, com até duas pessoas, e o percentual daquelas que recebem entre um e dois SM per capita por mês. Entretanto, e apesar disso, as famílias que recebem BPC são mais frequentes (70\%) nas classes econômicas D e E, comparativamente às demais (45\%) que não recebem qualquer benefício de TR. É provável, como observaremos mais adiante, que a escolaridade seja o fator que explique esta discrepância entre a renda e a classe econômica, já que esta última é influenciada pelos anos de frequência à escola da pessoa de referência da família.
Os domicílios onde ocorre recebimento do PBF abrigam famílias significativamente maiores e mais jovens do que as que não recebem essa TR. Nos primeiros domicílios, $73 \%$ das famílias têm quatro ou mais componentes, sendo de $40 \%$ nos últimos. Cerca de metade das famílias do PBF tem a idade da pessoa de referência abaixo dos quarenta anos, sendo de $39 \%$ naquelas que não recebem este benefício. Ainda são maiores nas famílias que têm recursos do PBF as proporções de pessoas de referência de cor negra (70\%) e de baixa escolaridade (81\% analfabetos ou com $1^{\circ}$ grau incompleto), que são duas reconhecidas condições de vulnerabilidade social e demográfica ilustradas no gráfico 3.

\section{- GRÁFICO 3: CARACTERÍSTICAS SOCIODEMOGRÁFICAS OBSERVADAS NOS DOMICÍLIOS SEGUNDO RECEBIMENTO DO PBF, BPC OU NÃO RECEBIMENTO DE TR, NO ESTRATO DE RENDIMENTO FAMILIAR MENSAL PER CAPITA ABAIXO DE DOIS SALÁRIOS MÍNIMOS (VALOR DO SM R\$ 415,00) - BRASIL}

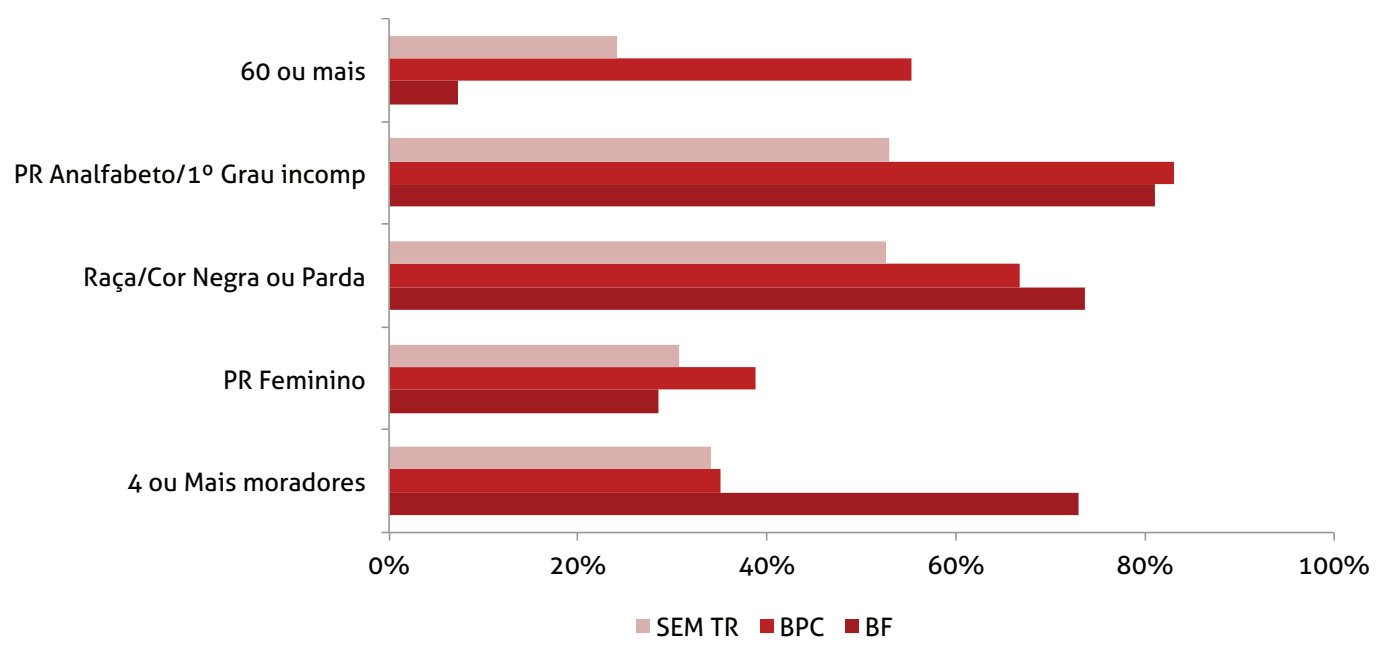

PR - Pessoa de referência

Fonte IBGE POF2008-2009

Gráfico produzido pelas autoras

12 Salário mínimo de $\mathrm{R} \$ 414,00$.

Revista Brasileira de Monitoramento e Avaliação | Número 4 | Julho-Dezembro de 2012

Análise do consumo de famílias de baixa renda elegiveis aos programas sociais de transferência de renda: Brasil-POF 2008-2009 
Mesmo situando a análise em rendimentos familiares mensais per capita abaixo de 2 SM, é possível observar que algumas características sociais e demográficas diferenciam os que recebem TR do BPC e os que não recebem. Diferentemente do que ocorre nos domicílios com famílias do PBF, naqueles que têm moradores recebendo BPC é mais alta e significativa a proporção de mulheres consideradas como de referência da família. Como esperado, essas famílias (BPC) têm distribuição etária favorecendo idades mais elevadas, entre eles $86 \%$ têm mais de quarenta anos, sendo $60 \%$ nesta idade a proporção entre os que não recebem TR deste programa. Também os domicílios com BPC têm a pessoa de referência com baixa escolaridade: $83 \%$ são analfabetos ou têm primeiro grau incompleto.

Na mesma faixa de rendimentos familiares per capita (abaixo de dois SMPC), é sistematicamente menor a capacidade de consumo das famílias que recebem recursos do PBF comparativamente àquelas que não recebem, considerando esse consumo medido pela posse de bens duráveis e por alguns tipos de serviços, como o de empregado doméstico e o de ser usuário de plano de saúde. Comparando os domicílios onde ocorre recebimento de PBF e de BPC, o perfil de consumo das famílias favorece estes últimos, com diferenças estatisticamente significativas, exceto em relação à posse de aparelho de videocassete. É possível que esta vantagem de consumo esteja relacionada não apenas aos valores maiores de TR nos domicílios com BPC mas também ao fato de que são famílias em faixas etárias superiores e, portanto, que tiveram oportunidade de mais tempo para acúmulo de bens. Por outro lado, os resultados mostram que, em geral, é baixo o perfil de consumo das famílias, independentemente do benefício recebido. Apenas a posse de TV em cores e geladeira ocorre com alta frequência, acima de 70\%, nos dois grupos de domicílio. 
- TABELA 1: CARACTERÍSTICA DE POSSE DE BENS DURÁVEIS E USO DE SERVIÇOS DOMÉSTICOS E NÃO DOMÉSTICOS SEGUNDO RECEBIMENTO DE PBF E BPC, CONSIDERANDO RENDIMENTO FAMILIAR MENSAL MENOR QUE DOIS SM PER CAPITA

\begin{tabular}{|c|c|c|c|c|}
\hline \multirow{3}{*}{ BENS E SERVIÇOS } & \multicolumn{4}{|c|}{ DOMICÍLIOS PARTICULARES E PERMANENTES } \\
\hline & \multicolumn{2}{|c|}{ PBF SIM } & \multicolumn{2}{|c|}{ BPC SIM } \\
\hline & TOTAL & $\%$ & TOTAL & $\%$ \\
\hline TV em cores & 2.076 & 100 & 209 & 100 \\
\hline $\operatorname{Sim}$ & 1.818 & 88 & 186 & 89 \\
\hline Não & 258 & 12 & 23 & 11 \\
\hline Videocassete/DVD* & 2.076 & 100 & 209 & 100 \\
\hline Sim & 1.170 & 56 & 101 & 48 \\
\hline Não & 906 & 44 & 108 & 52 \\
\hline Rádio & 2.076 & 100 & 209 & 100 \\
\hline Sim & 638 & 31 & 74 & 35 \\
\hline Não & 1.438 & 69 & 135 & 65 \\
\hline Automóvel & 2.076 & 100 & 209 & 100 \\
\hline Sim & 149 & 07 & 32 & 15 \\
\hline Não & 1.927 & 93 & 177 & 85 \\
\hline Computador & 2.076 & 100 & 209 & 100 \\
\hline Sim & 89 & 04 & 19 & 09 \\
\hline Não & 1.987 & 96 & 190 & 91 \\
\hline Motocicleta & 2.076 & 100 & 209 & 100 \\
\hline Sim & 353 & 17 & 25 & 12 \\
\hline Não & 1.723 & 83 & 184 & 88 \\
\hline Geladeira & 2.076 & 100 & 209 & 100 \\
\hline Sim & 1.608 & 77 & 181 & 87 \\
\hline Não & 468 & 23 & 28 & 13 \\
\hline Freezer & 2.076 & 100 & 209 & 100 \\
\hline Sim & 232 & 11 & 34 & 16 \\
\hline Não & 1.844 & 89 & 175 & 84 \\
\hline Máquina de lavar & 2.076 & 100 & 209 & 100 \\
\hline $\operatorname{Sim}$ & 302 & 15 & 29 & 14 \\
\hline Não & 1.774 & 85 & 180 & 86 \\
\hline Aspirador de pó & 2.076 & 100 & 209 & 100 \\
\hline Sim & 6 & 0 & 02 & 01 \\
\hline Não & 2.070 & 100 & 207 & 99 \\
\hline Domicílio tem empregado doméstico & 2.076 & 100 & 209 & 100 \\
\hline Sim & 21 & 01 & 07 & 03 \\
\hline Não & 2.055 & 99 & 202 & 97 \\
\hline PR tem plano de saúde & 1.936 & 100 & 201 & 100 \\
\hline Sim & 80 & 04 & 18 & 09 \\
\hline Não & 1.856 & 96 & 183 & 91 \\
\hline
\end{tabular}

*Valor de $p>0,05$.

Fonte IBGE POF2008-2009

Tabela produzida pelas autoras

Revista Brasileira de Monitoramento e Avaliação | Número 4 | Julho-Dezembro de 2012 
Assim como o padrão de rendimento difere entre os grupos analisados, como visto anteriormente, o mesmo ocorre com seu padrão de despesa. Os valores das despesas médias nos domicílios onde há recebimento de TR do PBF são sistematicamente menores do que aqueles verificados em domicílios com TR do BPC e, também, em relação aos domicílios sem TR. As médias nacionais de despesas mensais totais nos domicílios onde ocorrem PBF, BPC e onde não ocorre qualquer dos dois são respectivamente R\$959,00, R\$1200,00 e R\$1941 (gráfico 4). A região Nordeste tem médias menores que a nacional em todas as três situações. A média nacional de despesa mensal nos do- micílios com BPC é 20\% superior à verificada naqueles com PBF e de $37 \%$ comparando domicílios sem TR e aqueles com BPC. Os percentuais de diferenças, na comparação BPC e PBF, têm valores superiores na região Norte (28\%) e inferiores na região Sul (4\%). Chama a atenção o fato de que na região Sudeste os valores de despesa nos domicílios com PBF superam os verificados onde há BPC e, também, que nas duas regiões mais desenvolvidas, Sul e Sudeste, as despesas dos domicílios sem TR são o dobro das verificadas nos domicílios que têm recebimento de BPC. Esses resultados são consistentes com as diferenças observadas em relação ao rendimento das famílias.

\section{- GRÁFICO 4: VALOR MÉdIO MENSAL DE DESPESA DE CONSUMO (MONETÁRIA E NÃO MONETÁRIA) FAMILIAR ANUALIZADO SEGUNDO RECEBIMENTO OU NÃO DE PBF OU BPC, BRASIL E MACRORREGIÕES}

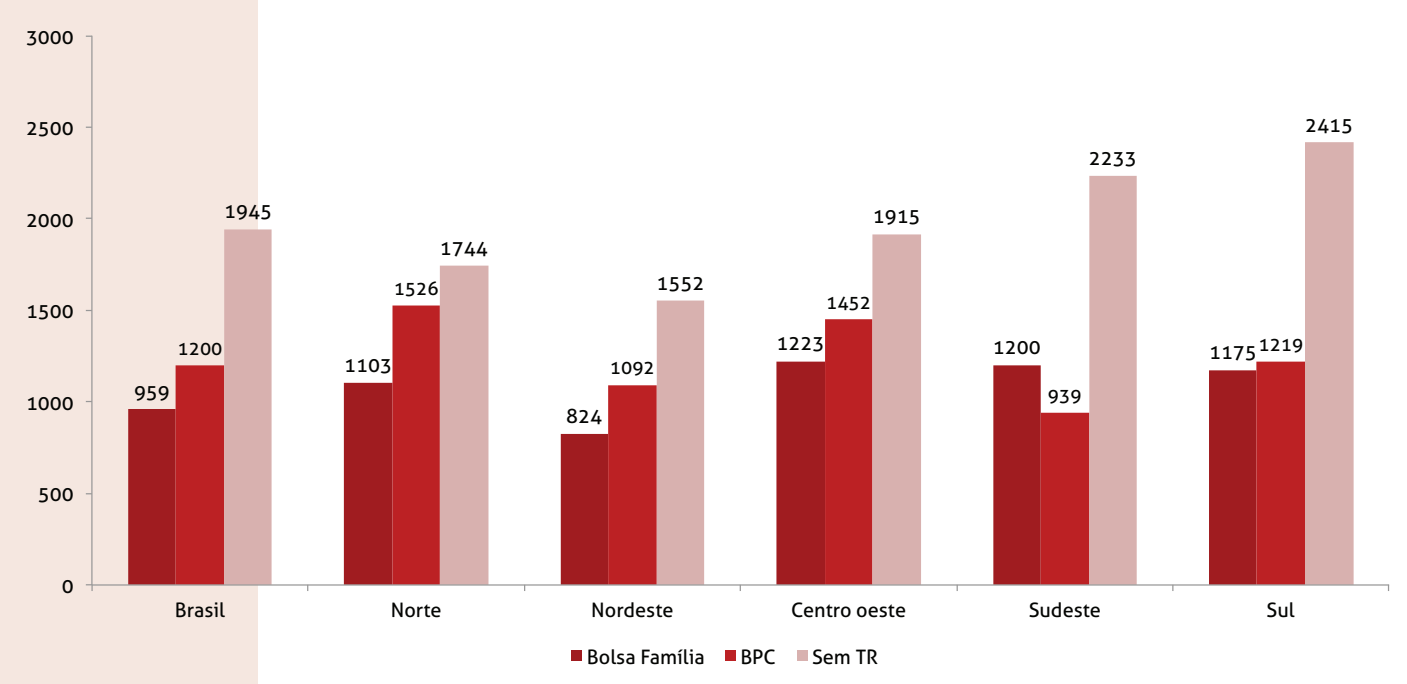

Fonte IBGE POF2008-2009

Gráfico produzido pelas autoras 
Para além das diferenças de despesas familiares observadas entre as regiões, há diferenças importantes se os domicílios são localizados em área urbana ou rural. Há predomínio de despesas mensais de consumo maiores em domicílios situados em áreas urbanas, considerando os três grupos populacionais analisados. É apenas na região Centro-Oeste em que a despesa média de consumo nos domicílios de titulares do BPC localizados em área rural supera os de área urbana. A menor média de consumo mensal de famílias titulares do PBF ocorre em domicílios de área rural da região Nordeste, sendo importante salientar que nesta situação estão os valores médios mais baixos de consumo considerando os três grupos, exceto para o BPC, em que a menor média situa-se na área rural do Sudeste.

A renda familiar e, portanto, o seu poder de consumo refletem as prioridades definidas pelas famílias na utilização e distribuição dos recursos de acordo com suas necessidades e estratégias. As despesas médias de consumo estão prioritariamente associadas aos gastos com alimentação e moradia em todas as regiões geográficas e em todos os grupos, sejam eles vinculados ao PBF, BPC ou sem vínculo com os programas. Estes itens representam mais de $50 \%$ do total de despesas, sendo que na região Nordeste ultrapassam 60\%. Em média as despesas com alimentação no Norte e Nordeste superam os valores das demais regiões, sendo que aquelas relativas à moradia são semelhantes e altas em todas as regiões.

Ao analisar os componentes das despesas, considerando o tipo de vínculo das famílias com os programas sociais, observamos que nos domicílios onde existem pessoas ligadas ao PBF, a despesa com alimentação supera aquela verificada nos domicílios com BPC e sem TR, exceto na região Centro-Oeste (gráfico 5). Nas regiões Norte e Nordeste, os gastos com alimentação representam mais de um terço do total das despesas. A alimentação e moradia, dois dos mais importantes itens das despesas familiares, representam para os titulares do PBF na região Norte $67 \%$ do total dos gastos, na região Nordeste $66 \%$, 59\% na região Centro-Oeste e 63\% no Sudeste e Sul.

Estes percentuais de gastos acima de $60 \%$ ocorrem entre os titulares do BPC no Nordeste, Centro- Oeste e Sudeste, porém nestas regiões a habitação tem o maior impacto nas despesas. Como esperado, nos domicílios onde não há moradores recebendo PBF ou BPC, os itens de despesa mais relevantes são, também, aqueles com a moradia. 
- GRÁFICO 5: VALOR MÉDIO MENSAL DE DESPESA DE CONSUMO (MONETÁRIA E NÃO MONETÁRIA) FAMILIAR ANUALIZADO EM DOMICÍLIOS COM RECEBIMENTO TR DE PBF, BPC E SEM RECEBIMENTO DE TR, SEGUNDO TIPO DE CONSUMO E LOCALIZAÇÃO GEOGRÁFICA - BRASIL
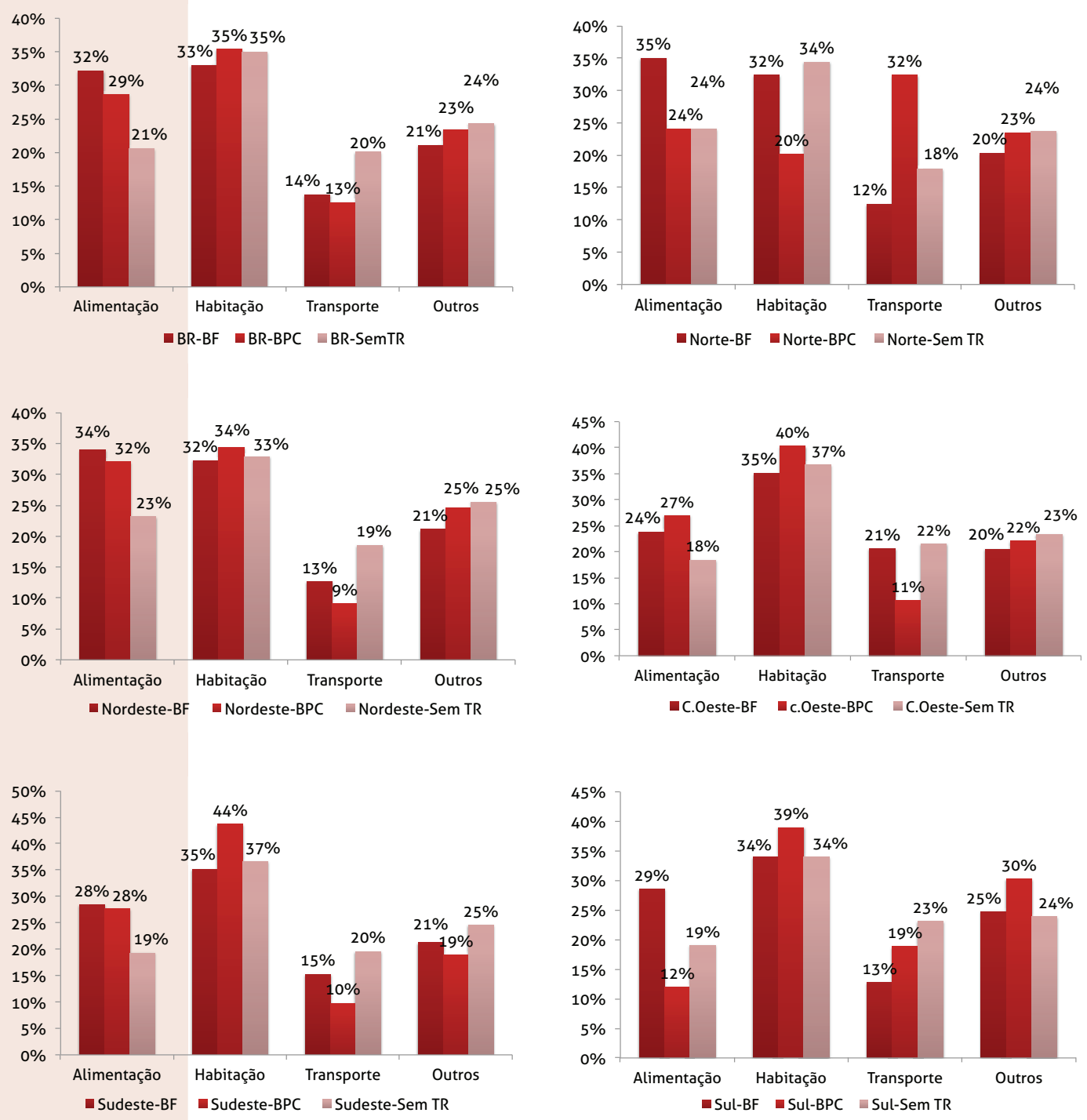

Fonte IBGE POF2008-2009

Gráfico produzido pelas autoras 
Os hábitos alimentares da população brasileira vêm se alterando profundamente nas últimas décadas ${ }^{13}$. Entre as modificações ocorridas está o progressivo aumento de refeições fora do domicílio. Isto tem a ver com a crescente urbanização e com os grandes deslocamentos de casa ao trabalho e vice-versa. Os dados das últimas POFs mostram as mudanças ocorridas na população gera ${ }^{14}$ e as diferenças regionais e socioeconômicas que explicam este fenômeno.

Os dados da POF 2008-2009, tomando como referência para sua análise os usuários de programas sociais, trazem resultados semelhantes aos verificados para a população geral, porém com diferenças de magnitude. As médias das despesas mensais com a alimentação fora do domicílio são maiores nas regiões Sudeste e Sul e menores no Norte e Nordeste, tendo a Centro-Oeste gastos intermediários. Estes gastos médios com alimentação fora de casa são sistematicamente menores, em todas as regiões, entre os titulares do BPC. Estes gastos elevam-se um pouco nos domicílios onde está presente o PBF e são significativamente maiores onde não há ocorrência de qualquer benefício de programas sociais do governo federal (gráfico 6). A explicação mais plausível para o baixo gasto com alimentação fora de casa entre usuários do BPC prende-se às características desse benefício, que está dirigido a idosos e portadores de algum tipo de deficiência.

\section{- GRÁFICO 6: DESPESAS COM ALIMENTAÇÃO NO DOMICÍlIO E FORA DO DOMICÍLIO SEGUNDO RECEBIMENTO OU NÃ̃ DE TR E REGIÃO GEOGRÁFICA DE RESIDÊNCIA}

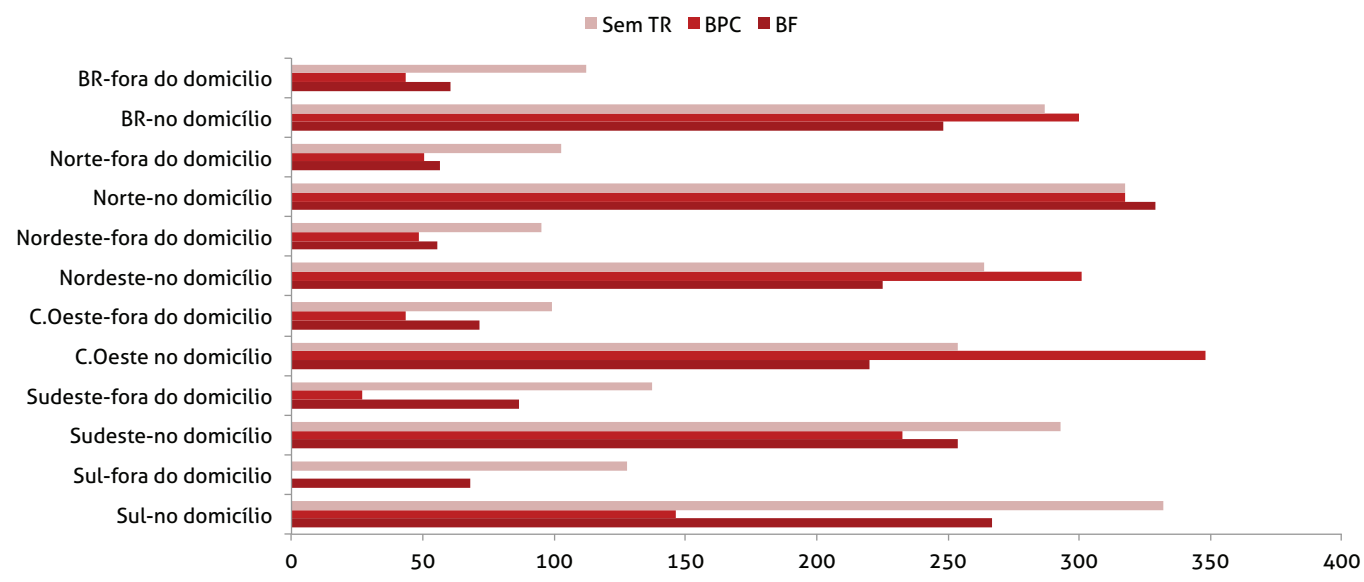

Fonte IBGE POF2008-2009

Gráfico produzido pelas autoras

13 (LEVY RB et al, 2011; LEVY-COOSTA, RB et al, 2005.)

14 (IBGE, 2004; IBGE, 2010.)

Revista Brasileira de Monitoramento e Avaliação | Número 4 | Julho-Dezembro de 2012

Análise do consumo de famílias de baixa renda elegiveis aos programas sociais de transferência de renda: Brasil-POF 2008-2009 
A distribuição dos gastos com alimentos, observada na Tabela 2, sugere que a compra dos alimentos sofre influência dos hábitos regionais e do custo dos itens ou grupos alimentares $^{15}$. Assim, em todas as regiões os maiores gastos são com o grupo de carnes, vísceras e pescados, seguidos pelas despesas com cereais, leguminosas e oleaginosas, depois aves e ovos e ainda os panificados, que aparecem com gastos significativos. Chama a atenção, entre os beneficiários do PBF, a magnitude dos gastos médios com alguns alimentos não saudáveis. Por exemplo, entre eles os gastos com óleos e gorduras superam as despesas com verduras e legumes, os gastos com açúcares superam os com frutas. Em certo grau isso diferencia os dois grupos. Nos domicílios onde existe alguém recebendo $\mathrm{BPC}$, os gastos com verduras e legumes superam aqueles verificados em domicílios onde ocorre recebimento de PBF. Por outro lado, as despesas com bebidas/infusões e com sal e condimentos são menores, exceto estes últimos nas regiões Norte e Nordeste.

TABELA 2: DISTRIBUIÇÃO DAS MÉDIAS MENSAIS DE DESPESAS COM ALIMENTAÇÃO NO DOMICÍLIO EM DOMICÍLIOS COM RECEBIMENTO E NÃO RECEBIMENTO DE PBF E BPC, SEGUNDO GRUPOS DE ALIMENTOS E GRANDES REGIÕES

\begin{tabular}{|c|c|c|c|c|c|c|c|c|c|c|}
\hline \multirow{4}{*}{ BRASIL E REGIÕES } & \multicolumn{10}{|c|}{ DOMICÍlios PARTICULARES E PERMANENTES } \\
\hline & \multicolumn{5}{|c|}{ PBF SIM } & \multicolumn{5}{|c|}{ BPC SIM } \\
\hline & Norte & $\begin{array}{l}\text { Nor- } \\
\text { deste }\end{array}$ & $\begin{array}{l}\text { Centro- } \\
\text { Oeste }\end{array}$ & $\begin{array}{l}\text { Su- } \\
\text { deste }\end{array}$ & Sul & Norte & $\begin{array}{l}\text { Nor- } \\
\text { deste }\end{array}$ & $\begin{array}{l}\text { Centro- } \\
\text { Oeste }\end{array}$ & $\begin{array}{l}\text { Su- } \\
\text { deste }\end{array}$ & Sul \\
\hline & $\begin{array}{l}\text { Méd } \\
(R \$)\end{array}$ & $\begin{array}{l}\text { Méd } \\
\text { (R\$) }\end{array}$ & $\begin{array}{l}\text { Méd } \\
\text { (R\$) }\end{array}$ & $\begin{array}{l}\text { Méd } \\
(R \$)\end{array}$ & $\begin{array}{l}\text { Méd } \\
\text { (RS) }\end{array}$ & $\begin{array}{l}\text { Méd } \\
\text { (R\$) }\end{array}$ & $\begin{array}{l}\text { Méd } \\
(\mathrm{R} \$)\end{array}$ & $\begin{array}{l}\text { Méd } \\
(R \$)\end{array}$ & $\begin{array}{l}\text { Méd } \\
(R \$)\end{array}$ & $\begin{array}{l}\text { Méd } \\
\text { (R\$) }\end{array}$ \\
\hline $\begin{array}{l}\text { Cereais, leguminosas e } \\
\text { oleaginosas }\end{array}$ & 37,1 & 32,4 & 34,5 & 28,3 & 29,9 & 28,4 & 27,7 & 32,0 & 23,6 & 10,4 \\
\hline Farinhas, féculas e massas & 25,8 & 17,5 & 11,1 & 12,2 & 20,5 & 30,7 & 20,6 & 10,1 & 9,3 & 10,0 \\
\hline Açúcar/derivados & 12,7 & 9,4 & 12,8 & 14,5 & 15,6 & 12,4 & 10,6 & 10,5 & 16,0 & 7,2 \\
\hline Legumes/verduras & 8,1 & 7,3 & 8,0 & 8,7 & 7,7 & 10,7 & 11,2 & 11,3 & 10,6 & 7,2 \\
\hline Frutas & 10,5 & 8,7 & 7,9 & 7,4 & 9,3 & 9,9 & 15,8 & 12,4 & 5,9 & 7,8 \\
\hline Carnes, vísceras e pescados & 102,0 & 50,5 & 42,4 & 52,2 & 49,3 & 91,6 & 66,4 & 107,7 & 45,9 & 45,7 \\
\hline Aves e ovos & 35,9 & 25,1 & 16,7 & 18,8 & 23,3 & 36,7 & 30,6 & 33,1 & 19,6 & 20,0 \\
\hline Leites e derivados & 20,4 & 17,2 & 21,6 & 30,0 & 26,2 & 28,1 & 26,8 & 24,3 & 36,5 & 6,4 \\
\hline Panificados & 27,8 & 23,5 & 18,8 & 29,4 & 23,0 & 23,8 & 27,3 & 22,3 & 26,5 & 12,8 \\
\hline Óleos e gorduras & 9,4 & 6,3 & 8,4 & 7,9 & 8,2 & 8,0 & 6,0 & 6,9 & 9,3 & 4,2 \\
\hline Bebidas/ infusões & 26,3 & 12,7 & 19,8 & 19,7 & 25,5 & 22,2 & 17,2 & 15,7 & 14,2 & 8,7 \\
\hline Alimentos preparados & 2,4 & 2,4 & 2,1 & 3,8 & 1,4 & 0,0 & 2,6 & 11,7 & 1,6 & 1,2 \\
\hline Tubérculos/raízes & 2,6 & 3,0 & 4,4 & 3,9 & 5,9 & 1,6 & 5,3 & 4,7 & 2,5 & 4,2 \\
\hline Enlatados e conservas & 1,8 & 1,3 & 1,5 & 1,0 & 1,2 & 1,1 & 2,9 & 2,2 & 1,6 & 0,0 \\
\hline Sal/ condimentos & 5,0 & 3,3 & 7,8 & 6,8 & 8,8 & 10,5 & 4,3 & 6,2 & 7,0 & 0,6 \\
\hline Outros & 1,2 & 4,3 & 2,2 & 9,3 & 11,1 & 1,4 & 25,7 & 37,1 & 2,3 & 0,0 \\
\hline Total Domicílio & 329,2 & 225,0 & 219,9 & 253,9 & 266,8 & 317,2 & 301,0 & 348,3 & 232,5 & 146,3 \\
\hline
\end{tabular}

Fonte IBGE POF2008-2009

Tabela produzida pelas autoras 
A POF 2008-200916 incluiu um módulo em seu questionário sobre a percepção de algumas condições ligadas à qualidade de vida, incluindo indicadores domiciliares sobre suficiência ou não de recursos monetários até o final do mês, de alimentos em termos de quantidade e, por fim, de preferência.

Inicialmente, foi perguntado com que grau de facilidade/ dificuldade o dinheiro disponível na casa era suficiente para passar o mês. As respostas possíveis eram as categorias de "muita dificuldade", "dificuldade", "alguma dificuldade", "facilidade" e "muita facilidade". Os gráficos a seguir tratam a análise destes aspectos agrupando as três primeiras categorias em "dificuldade" e as demais em "facilidade". Isto foi necessário dado o tamanho da amostra disponível para análise destas condições nos grupos que recebem TR do PBF ou do BPC.

Em termos nacionais, tanto em áreas urbanas quanto rurais, é alta (85\%) a frequência de domicílios com titulares de TR do PBF que referem dificuldades relativas à suficiência, em algum grau, de recursos para as despesas mensais, ou seja, que o dinheiro disponível não dá para o mês inteiro. Em todas as regiões do País, exceto a região Norte, aqueles que residem em área urbana relatam maior deficiência desses recursos (Gráfico 7). Os titulares do BPC também têm alta frequência de relato de insuficiência de recursos para as despesas mensais, apesar de ser em menor magnitude do que ocorre entre os domicílios do PBF. O padrão urbano-rural relatado acima também é observado quando é analisada a experiência das famílias em que há recebimento de BPC. Entretanto, as diferenças entre os residentes em área urbana e rural têm dimensões muito maiores do que aquelas apresentadas pelos domicílios do PBF. Em outras palavras, as famílias residentes em área rural estão um pouco mais protegidas desta insuficiência de recursos. A menor diferença percentual, entre rural e urbano, é observada no Sudeste $(2,2 \%)$ e a maior no Centro-Oeste (40,5\%). 
- GRÁFICO 7: AVALIAÇÃO DO GRAU DE DIFICULDADE PARA CHEGAR AO FIM DO MÊS COM VALOR DOS RENDIMENTOS SUFICIENTE PARA AS DESPESAS EM DOMICÍLIOS ONDE HÁ RECEBIMENTO DO PBF E BPC, SEGUNDO A REGIÃO GEOGRÁFICA E SITUAÇÃO RURAL/URBANA DO DOMICÍLIO - BRASIL

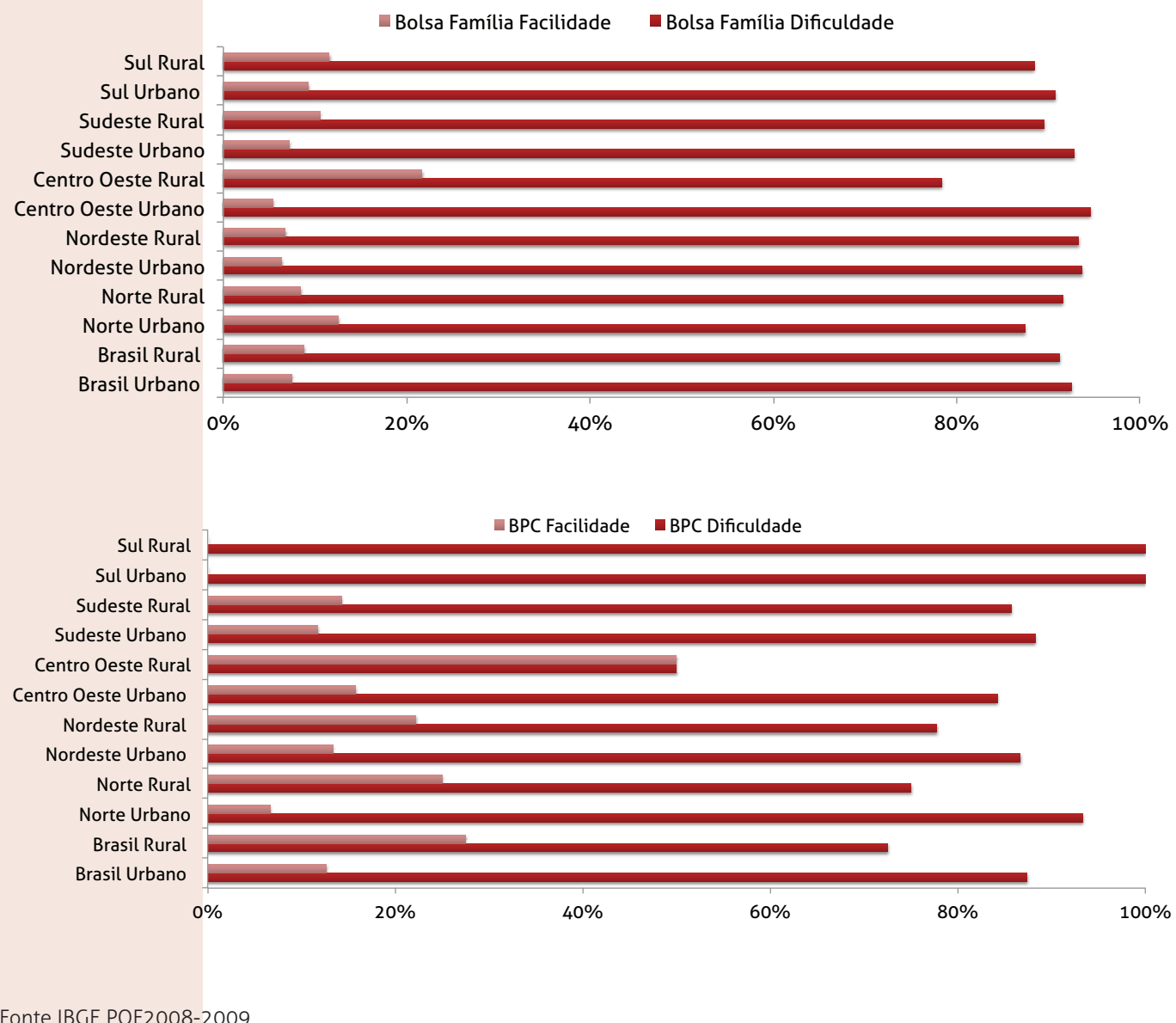

Fonte IBGE POF2008-2009

Gráfico produzido pelas autoras

A segunda observação sobre condições de vida refere-se à percepção quanto à suficiência de alimentos para a família. A pergunta formulada aos titulares do PBF e BPC considerava possível a disponibilidade dos alimentos em gradiente de três níveis, no gráfico 8 categorizadas como: "sempre suficiente", "às vezes suficiente" e "insuficiente. No Brasil, apenas 19\% e $21 \%$ dos titulares do PBF residentes em área urbana e rural, respectivamente, referiram que a quantidade de alimentos consumida pela família era sempre suficiente. Por outro lado, outros 34\% disseram que normalmente esse consumo não era suficiente. Contrariamente ao esperado, o percentual de insatisfação com o consumo de alimentos é mais elevado nas regiões Centro-Oeste, Sudeste e Sul. Também para essa condição, a pior situação é relatada entre os recebem TR do PBF nas áreas urbanas, exceto no Nordeste. 


\section{GRÁFICO 8: AVALIAÇÃO DA PERCEPÇÃO SOBRE A SUFICIÊNCIA DOS}

ALIMENTOS CONSUMIDOS EM DOMICÍLIOS ONDE HÁ RECEBIMENTO DE TR DO PBF E DO BPC E ONDE NÃO HÁ TR, SEGUNDO MACRORREGIÕES E SITUAÇÃO URBANA/RURAL

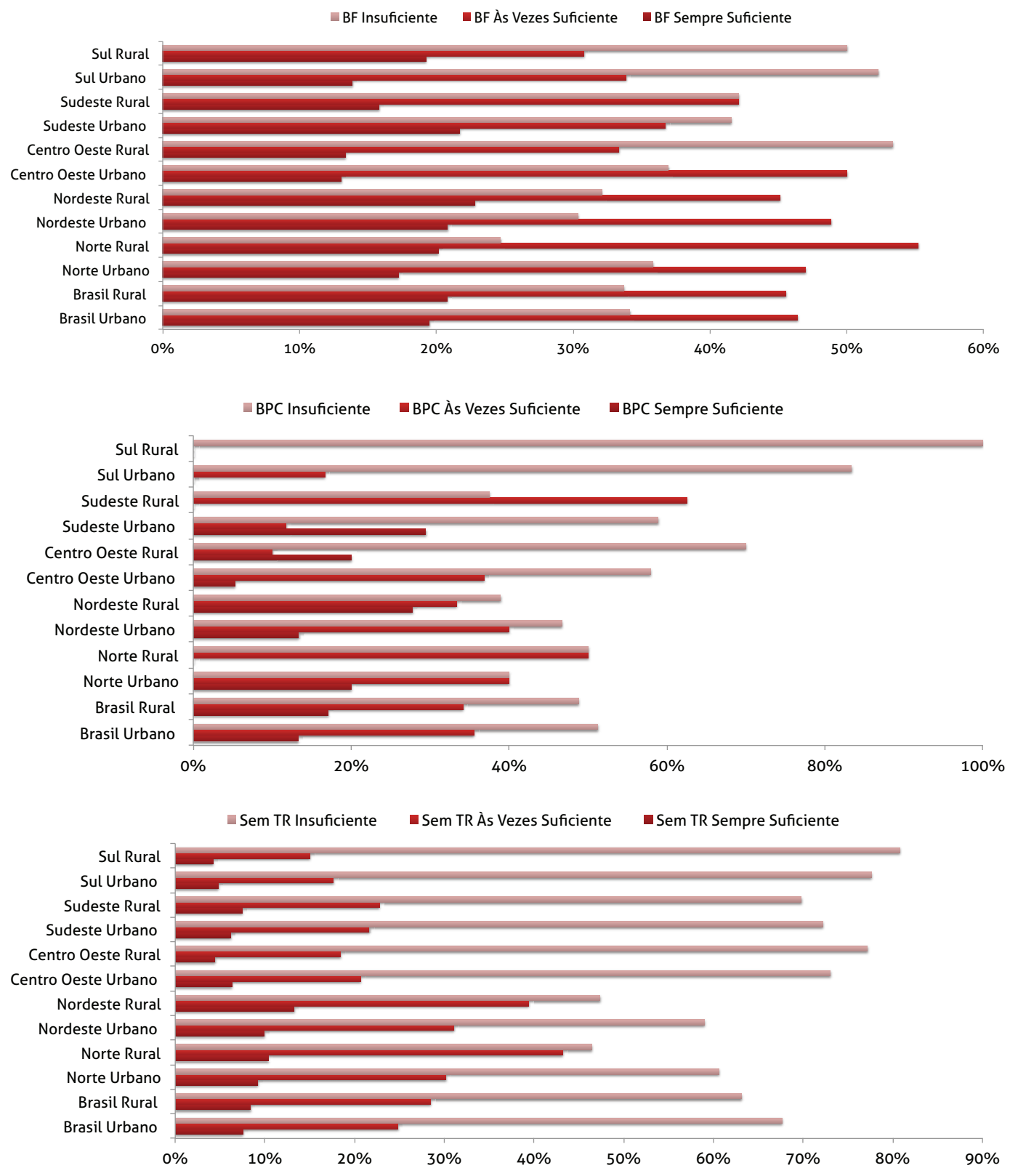

Fonte IBGE POF2008-2009

Gráfico produzido pelas autoras

Revista Brasileira de Monitoramento e Avaliação | Número 4 | Julho-Dezembro de 2012 
Em relação ao BPC, há sempre dificuldade na análise devido à menor cobertura populacional e, portanto, de representação na amostra. Mesmo assim é possível observar que é percentualmente mais elevada a referência a consumo normalmente insuficiente. As mais baixas referências a esta situação são no Norte e no Nordeste, $42 \%$ e $45 \%$ respectivamente, e a mais alta ocorre no Centro-Oeste, que é de $60 \%$. A região Sul não alcança número suficiente de pessoas para que seja considerada a sua frequência de $83 \%$. É interessante notar que se forem consideradas a média nacional e das regiões, a pior situação de referência de consumo normalmente insuficiente ocorre entre os não usuários do BPC e do PBF. Para essa população, as mais altas frequências dessa condição estão nas áreas urbanas do Norte, Nordeste e Sudeste e nas áreas rurais do Centro-Oeste e do Sul.

Outra pergunta importante deste módulo, sobre avaliação da qualidade de vida da POF 2008-2009, refere-se à adequação da dieta aos hábitos e expectativa de consumo alimentar da população. Foi perguntado ao entrevistado se os alimentos consumidos pela família eram: "do tipo que a família quer", "nem sempre do tipo que quer" e "raramente do tipo que quer". Os resultados relativos aos titulares do PBF e BPC mostram, na percepção dos entrevistados, uma grande inadequação do padrão de consumo alimentar destes grupos. No País, apenas $13 \%$ dos beneficiários do PBF referem consumo de acordo com suas preferências. As maiores proporções de satisfação com o consumo alimentar entre os participantes do PBF foram observadas na região Norte (17\%), áreas rurais do Centro-Oeste (18\%) e do Sul (23\%). Ressalte-se ainda que os percentuais de satisfação dos titulares do PBF são muito inferiores ao grau de insatisfação medido pela resposta "raramente o preferido". O primeiro (satisfação) varia nas regiões entre $11 \%$ e $23 \%$, enquanto que a insatisfação com o tipo de alimento consumido varia de $15 \%$ a $31 \%$. 
Por outro lado, a proporção média no Brasil de satisfação com a dieta entre titulares do BPC (28\%) é superior ao dobro da verificada nos domicílios com PBF. O grau de satisfação é maior na região Centro-Oeste (38\%), Nordeste (29\%) e Sul (29\%). Apesar da diferença observada e favorável aos domicílios com BPC relativamente ao grau de satisfação familiar com o tipo de alimento consumido, eles são muito inferiores ao da população residente em domicílios que não recebem TR. A proporção média nacional de satisfação é de $38 \%$, chegando a $47 \%$ na área rural da região Centro-Oeste. Ainda foram perguntadas outras questões ligadas à qualidade de vida, percepção de necessidades e razão pelo não atendimento daquilo considerado desejável. Por exemplo, à pergunta, "Oual a razão de sua família não estar se alimentando do tipo que quer?", 83\% dos entrevistados de domicílio onde havia recebimento do $\mathrm{PBF}$ responderam que a renda familiar não permitia isso, $66 \%$ e
55\% dos domicílios com BPC e sem TR, respectivamente, deram a mesma resposta.

Várias outras perguntas acerca de satisfação com serviços públicos como saúde, educação e transporte público fazem emergir respostas negativas em proporções muito elevadas, e algumas delas semelhantes nos três grupos. Isto atesta uma insatisfação geral, ainda que algumas situações sejam mais críticas para os domicílios do PBF. Por outro lado, é interessante notar que as expectativas podem ser diferentes entre os grupos. Perguntados sobre a renda mensal mínima para chegar até o fim do mês, os valores referidos são menores entre entrevistados de domicílios urbanos com PBF (R\$1.100,00) comparativamente ao BPC $(R \$ 1.493,00)$ e aos domicílios sem TR (R\$2.298). O mesmo comportamento, valores menores referidos em domicílios com PBF, ocorreu em relação à pergunta sobre os recursos necessários para a alimentação.

Revista Brasileira de Monitoramento e Avaliação | Número 4 | Julho-Dezembro de 2012 


\section{Conclusão}

Os resultados desta análise apontam maiores condições de vulnerabilidades sociais, econômicas, demográficas e ambientais nos domicílios onde residem pessoas que recebem recursos de transferência de renda dos programas sociais do governo federal. Estas condições são mais desfavoráveis nos domicílios do PBF. Ilustrando esta situação está o fato de que a mediana dos rendimentos familiares per capita é duas vezes superior nos domicílios que recebem o BPC.

Os rendimentos familiares per capita observados nos domicílios com PBF atestam a baixa capacidade de consumo destas famílias. Considerando, para fins comparativos, o estrato de renda abaixo de dois SM, observa-se que é sistematicamente baixa a capacidade de consumo das famílias que recebem recursos do PBF quando esse consumo é medido pela posse de bens duráveis e por alguns tipos de serviços, como o de empregado doméstico, ser usuário de plano de saúde, além do baixo acesso a outros serviços públicos, como o de saneamento.
Outras condições de vulnerabilidades daqueles beneficiados por TR dos programas sociais agravam a situação descrita. Os domicílios onde ocorre recebimento do PBF abrigam famílias com número maior de moradores, com pessoa de referência mais jovem, de baixa escolaridade e de raça/cor negra.

Por outro lado, a comparação entre os domicílios que recebem BPC, os que recebem PBF e aqueles que não recebem TR mostra que aquela transferência de renda (BPC) pode ter impactado positivamente as condições sociais e de consumo destas famílias com idosos. A análise dos dados permitiu ainda observar a congruência entre os padrões de rendimento dos três grupos populacionais (PBF, BPC e o grupo sem TR) com o perfil de seus gastos. Os valores das despesas médias nos domicílios onde há recebimento de TR do PBF são em todas as regiões do País menores do que aqueles verificados em domicílios com TR do BPC e, também, em relação aos domicílios sem TR, exceto na região Sudeste, onde os gastos médios nos domicílios 
do PBF superam as despesas daqueles com BPC. Além disso, as despesas das famílias residentes em áreas urbanas são sistematicamente maiores do que aquelas de área rural, independentemente do grupo estudado ou região do País.

Como dito anteriormente, a renda familiar e, portanto, o seu poder de consumo refletem as prioridades definidas pelas famílias na utilização e distribuição dos recursos de acordo com suas necessidades e estratégias. Dois componentes das despesas, alimentação e moradia, destacam-se em relação aos demais em todas as regiões do País, considerando os grupos do PBF, BPC e aquele sem TR.

Deve ser destacado o fato de que os gastos com a alimentação são mais elevados nas regiões mais pobres do País (Norte e Nordeste) e entre as famílias beneficiárias do PBF, que representam o segmento analisado de rendimentos médios mais baixos. Por outro lado, a alimentação fora de casa compromete mais os rendimentos das famílias de áreas urbanas e das regiões Sul e Sudeste.

Os itens alimentares que mais pesam no orçamento familiar são os básicos da dieta brasileira, como cerais, leguminosas, carnes em geral e massas (farinhas e panificados). Entretanto, como já observado em análise dos dados gerais da POF, há consumo (gastos familiares) excessivo de itens alimentares pouco ou não saudáveis. É preocupante o fato de que este consumo se destaca nos domicílios onde está presente o PBF, indicando a necessidade de outras medidas de políticas públicas ao lado de ações de educação alimentar.

A análise dos dados referentes à percepção de qualidade de vida das famílias que recebem TR dos programas sociais, sobretudo o PBF, confirmam e dão consistência aos resultados relatados anteriormente. No Brasil, mais de $80 \%$ dos entrevistados de domicílios com TR do PBF referiram que em algum grau o dinheiro disponível não era suficien-

Revista Brasileira de Monitoramento e Avaliação | Número 4 | Julho-Dezembro de 2012 
te para atender às despesas do mês inteiro. Essa insuficiência de recursos é ainda mais frequente nas áreas urbanas, provavelmente pelo atendimento a necessidades básicas, como transporte para o trabalho, alimentação fora de casa, vestuário e outros, que demandam menos recursos em área rurais.

Provavelmente como consequência da insuficiência de recursos, mais de um terço dos domicílios onde residem famílias que recebem TR do PBF relatam que normalmente não consomem alimentos em quantidade suficiente. Agravando esta situação, também há referência com percentual elevado, superior a $80 \%$, de que os alimentos consumidos pela família não são aqueles de sua preferência. Não é possível esclarecer o significado do ponto de vista qualitativo da dieta, mas é justificável concluir que o consumo alimentar dessas famílias não atende às expectativas dos há- bitos alimentares e culturais desse grupo. 0 mesmo ocorreu, em frequência menor, nos domicílios com BPC.

Como referido anteriormente, houve restrições para as análises dos usuários do BPC devido à pequena representação deste grupo no banco de dados. Mesmo assim, muitos dos resultados apresentados são consistentes com o esperado para este grupo. Provavelmente, o fundamental é a constatação de um possível impacto do BPC, dado o valor da TR, nas condições de consumo e vida de seus usuários.

Muito ainda se pode avançar nas análises dos dados da POF relativamente a esses grupos mais vulneráveis da população brasileira. Entretanto, os resultados aqui apresentadas podem ser de muita utilidade para os gestores das políticas sociais que aqui foram indiretamente analisadas. 
ASSOCIAÇÃO BRASILEIRA DE EMPRESAS DE PESOUISAS (ABEP). Critério padrão de classificação econômica Brasil 2008. Junho 2007. Disponível em: <www.abep.org/codigosguias/Criterio_ Brasil_2008.pdf>. Acesso em: fev. 2012.

COELHO, A. B.; AGUIAR, D. R. D.; FERNANDES, E. A. Padrão de consumo de alimentos no Brasil. Rev. Econ. Social Rural, v. 47, n. 2, p. 335362, 2009. ISSN 0103-2003. Disponível em: $<$ http://www.scielo.br/scielo.php?script=sci_ arttext\&pid=S0103-20032009000200002\&ln $\mathrm{g}=$ en\&nrm=iso>.

INSTITUTO BRASILEIRO DE GEOGRAFIA E ESTATÍsTICA (IBGE). Pesquisa Nacional por Amostra de Domicílios - Suplemento de Segurança Alimentar. Rio de Janeiro, 2006. 148 p. ISBN 852403869-1. Disponível em: <mds2/servicos/ estatisticas/estatisticas/PNADSegurancaAlimentar2004.pdf>.

INSTITUTO BRASILEIRO DE GEOGRAFIA E ESTATÍSTICA (IBGE). Pesquisa de Orçamentos familiares 2002 -2003: análise da disponibilidade domiciliar de alimentos e estado nutricional no Brasil. Rio de Janeiro, 2004.

INSTITUTO BRASILEIRO DE GEOGRAFIA E ESTATísTICA (IBGE). Pesquisa de Orçamentos Familiares 2008 -2009: antropometria e estado nutricional de crianças e adolescentes e adultos no Brasil. Rio de Janeiro, 2010.
LEVY, R. B. et al. Distribuição regional e socioeconômica da disponibilidade domiciliar de alimentos no Brasil em 2008-2009. Rev. Saúde Pública, v. 46, n. 1, p. 06 -15, 2012. Disponível em: <http://www.scielo.br/scielo.php?script=sci_ arttext\&pid $=$ S0034-89102012000100002\&ln $\mathrm{g}=$ enfnrm=iso. Epub Dec 20, 2011>.

LEVY-COSTA, R. B.; SICHIERI, R.; PONTES, S. N., MONTEIRO, C. A. Disponibilidade domiciliar de alimentos no Brasil: distribuição e evolução (1974-2003). Rev. Saúde Pública, v. 39, n. 4, p. 530-540, 2005. ISSN 00348910. Disponível em: <http://www.scielo.br/ scielo.php?script $=$ sci_arttext\&pid $=$ S0034$-89102005000400003 \&$ lng $=$ en\&nrm $=$ iso $>$.

SEGALL-CORRÊA A. M.; LEON-MARIN, P. G., PEREZ-ESCAMILLA R. Segurança Alimentar em Domicílio. In: BEROUÓ, Elza; GARCIA, Sandra; LAGO, Tânia (Ed.). PNDS 2006. Brasilia: Ministério da Saúde, 2008, p. 306. Disponível em: <http://bvsms.saude.gov.br/bvs/publicacoes/ pnds_crianca_mulher.pdf>.

SOUZA, A. M. et al. Alimentos mais consumidos no Brasil: Inquérito Nacional de Alimentação 2008-2009. Revista de Saúde Pública, v. 47, p. 190s-199s, 2013.

Revista Brasileira de Monitoramento e Avaliação | Número 4 | Julho-Dezembro de 2012

Análise do consumo de famílias de baixa renda elegiveis aos programas sociais de transferência de renda: Brasil-POF 2008-2009 